OPEN ACCESS

Edited by:

Chiara Magliaro,

University of Pisa, Italy

Reviewed by:

Shigeki Kato,

Fukushima Medical University, Japan

Xiaojun Wang,

Hainan University, China

Daniel Normen Düring,

ETH Zürich, Switzerland

*Correspondence:

Jinhyun Kim

jinnykim@me.com

tThese authors have contributed equally to this work and share first

authorship

Received: 31 March 2021 Accepted: 28 May 2021

Published: 21 June 2021

Citation:

Yook JS, Kim J and Kim J (2021)

Convergence Circuit Mapping: Genetic Approaches From Structure

to Function.

Front. Syst. Neurosci. 15:688673. doi: 10.3389/fnsys.2021.688673

\section{Convergence Circuit Mapping: Genetic Approaches From Structure to Function}

\author{
Jang Soo Yook ${ }^{1+}$, Jihyun $\mathrm{Kim}^{1,2+}$ and Jinhyun Kim ${ }^{1,2 *}$ \\ ${ }^{1}$ Center for Functional Connectomics, Korea Institute of Science and Technology (KIST), Seoul, South Korea, ${ }^{2}$ Department \\ of Integrated Biomedical and Life Sciences, Graduate School, Korea University, Seoul, South Korea
}

Understanding the complex neural circuits that underpin brain function and behavior has been a long-standing goal of neuroscience. Yet this is no small feat considering the interconnectedness of neurons and other cell types, both within and across brain regions. In this review, we describe recent advances in mouse molecular genetic engineering that can be used to integrate information on brain activity and structure at regional, cellular, and subcellular levels. The convergence of structural inputs can be mapped throughout the brain in a cell type-specific manner by antero- and retrograde viral systems expressing various fluorescent proteins and genetic switches. Furthermore, neural activity can be manipulated using opto- and chemo-genetic tools to interrogate the functional significance of this input convergence. Monitoring neuronal activity is obtained with precise spatiotemporal resolution using genetically encoded sensors for calcium changes and specific neurotransmitters. Combining these genetically engineered mapping tools is a compelling approach for unraveling the structural and functional brain architecture of complex behaviors and malfunctioned states of neurological disorders.

Keywords: viral tracers, optogenetics, chemogenetics, genetically encoded calcium indicators, genetically encoded transmitter indicators, synapse, brain mapping

\section{INTRODUCTION}

Information is processed in the brain by a vast number of diverse neurons that are extensively intermingled and interconnected mainly through synapses. Structural and functional analyses of neural circuits are essential for deciphering the operational principles of the brain. Neurons often convey multiple layers of information converging from various cell types and/or brain areas, with integration of these signals coordinating a variety of behaviors and cognitions. To understand highly regulated and complex information processing in neural networks, knowledge of afferent input organization is crucial because functions of certain neurons within a brain region are shaped by the profiles of their inputs as initial signals. Therefore, increasingly, scientific endeavors are ongoing to untangle convoluted neural circuits at different levels (synapse-neuron-region) in various organisms (White et al., 1986; Stephan et al., 2001; Kötter, 2004; Sporns et al., 2005; Bock et al., 2011; Briggman et al., 2011; Van Essen et al., 2013; Oh et al., 2014; Hildebrand et al., 2017; Cook et al., 2019; Scheffer et al., 2020), generally starting with connections between defined populations of neurons and cell types (Druckmann et al., 2014; Kasthuri et al., 2015; Iascone et al., 2020). Developing and improving new technologies for identifying, labeling, imaging, and 
manipulating individual neurons, as well as populations of neurons in the context of behaviors, will lead to a comprehensive picture of neural network organization (Micheva and Smith, 2007; Kim et al., 2011; Yizhar et al., 2011; Ragan et al., 2012; Sternson and Roth, 2014; Lin and Schnitzer, 2016; Kornfeld and Denk, 2018). The initial step in these connectivity research studies relies on genetic engineering: well-established animal models expressing genetic switches, such as Cre and tetracyclinecontrolled transactivator, for defining and labeling certain populations and types of neurons (Sauer and Henderson, 1988; Gossen and Bujard, 1992; Gong et al., 2007; Gerfen et al., 2013; Harris et al., 2014, 2019; Hooks et al., 2018); viral systems with different features, such as tropism and axonal transduction, in a genetic switch-dependent manner (DeFalco et al., 2001; Wall et al., 2010; Lo and Anderson, 2011; Ährlund-Richter et al., 2019; Lazaridis et al., 2019; Sun et al., 2019; Gong et al., 2020); fluorescent sensors for monitoring neural events, such as intracellular $\mathrm{Ca}^{2+}$ influx and neurotransmitter release in response to neural activity (Lin and Schnitzer, 2016; Sabatini and Tian, 2020); and actuators for manipulating neuronal activity, such as opto- and chemo-genetics (Deisseroth, 2015; Roth, 2016; Atasoy and Sternson, 2018). The next step requires advances in imaging and reconstruction of genetically defined neural populations, and in sophisticated behavioral measurements linking the wiregram and dynamics of neural circuits to behaviors (Ragan et al., 2012; Gong et al., 2016; Harris et al., 2019; Wang et al., 2020).

The field of neuroscience has been rapidly and dramatically changing in the last two decades, fueled by innovations in molecular genetic engineering, imaging, and computer science. Recently equipped with advanced tools including microscopes and optrodes (Flusberg et al., 2008; Ghosh et al., 2011; Cui et al., 2013; Kim C.K. et al., 2016; Sofroniew et al., 2016; Zong et al., 2017; Skocek et al., 2018; Sych et al., 2019), researchers are increasingly capable of monitoring and perturbing the activity of specific types and populations of neurons as well as dissecting complex neural connectivity. It is no exaggeration to state that at the core of these advanced versatile tool boxes there are genetic tools making it possible to deliver tailored detectors, sensors, and manipulators to specific circuits, neurons, and synapses for studying the convergence of multiple information in the brain. Here, with particular attention to genetic approaches, we review the advanced tools for structural and functional mapping of convergence connectivity now available to neuroscientists working in the mouse. Beginning with a brief technical account and discussion of the unique significance of these approaches, we then discuss recent advances in their applications and combinatorial strategies for exploring structural and functional organization of various circuits.

\section{Structural Input Convergence Mapping With Anterograde Viral Tracers}

A plethora of neuronal input studies have emerged from the idea that complex brain functions are operated by signal integration of various inputs and coordination of neural activity at the network level. One straightforward approach has been labeling of a certain neural population in a brain area with anterograde tracers and examination of the labeled axonal projections (Hunnicutt et al., 2014, 2016; Oh et al., 2014). Collective data from separate experiments labeling various neural populations, maximally two or three at once, illustrated convergence inputs. Owing to limitations of classical non-viral tracers, such as biotinylated dextran amine, we have focused on recombinant adeno-associated virus (rAAV) as the most commonly chosen anterograde viral tracer. Several reviews have extensively covered the limitations of conventional non-viral tracers (Nassi et al., 2015; Saleeba et al., 2019). In fact, synergetic application of anterograde AAVs expressing fluorescent proteins (FPs), advanced imaging techniques, and computational methods, have recently generated brain-wide and large-scale connectivity data that provide a comprehensive convergence map (Ragan et al., 2012; Hunnicutt et al., 2014, 2016; Oh et al., 2014; Kuan et al., 2015; Winnubst et al., 2019; Wang et al., 2020; Figure 1).

\section{Anterograde Viral Systems}

Viral vectors are a powerful tool for gene delivery in the nervous system, and in particular, rAAV is proven as an optimal gene delivery system with safety, efficiency, and practical ease (Wang et al., 2014; Haggerty et al., 2020; Xu et al., 2020). Given the technical advantages of rAAV, recent studies of input mapping have used rAAV-expressing FPs as reliable anterograde tracers. For instance, rAAV-expressing EGFP has been stereotaxically injected into various brain areas (Hunnicutt et al., 2014, 2016; Oh et al., 2014). Advances in imaging and computer capabilities made a standardized data generation and processing platform possible, thereby axonal projections were digitally traced throughout the whole mouse brain. These detailed high-resolution images and anatomically defined input/target areas are accessible in online resources (i.e., Allen Brain Map ${ }^{1}$ ). The Allen Mouse Common Coordinate Framework provides a fully digitalized three-dimensional (3D) average brain image. A labeled brain region space (Allen CCF v3 Brain Atlas) facilitates systematic analysis of input/output profiles throughout the whole brain. Taking advantage of these standardized and digitalized platforms, axonal projection datasets from various brain regions can be reconciled to generate a map of convergent circuitry, despite data being obtained through separate experimental performances. Furthermore, detailed descriptions of topographical patterns of these axonal projections to a target region (converged from various spatially and functionally segregated input areas) captures important information on the organization principles of neural underpinnings. These recent studies have delineated convergent circuitries suggesting rules of connectivity organization and functional domains, with particular attention to cortical inputs to the thalamus and striatum, thalamic nuclei inputs to the cortex, and thalamic inputs to the striatum.

Notably, there are interesting investigations using rAAVmediated anterograde trans-synaptic tagging, although rAAV is generally known to be transduced via anterograde single-cycle infection rather than trans-neuronal/trans-synaptic transduction

${ }^{1}$ http://www.brain-map.org/ 


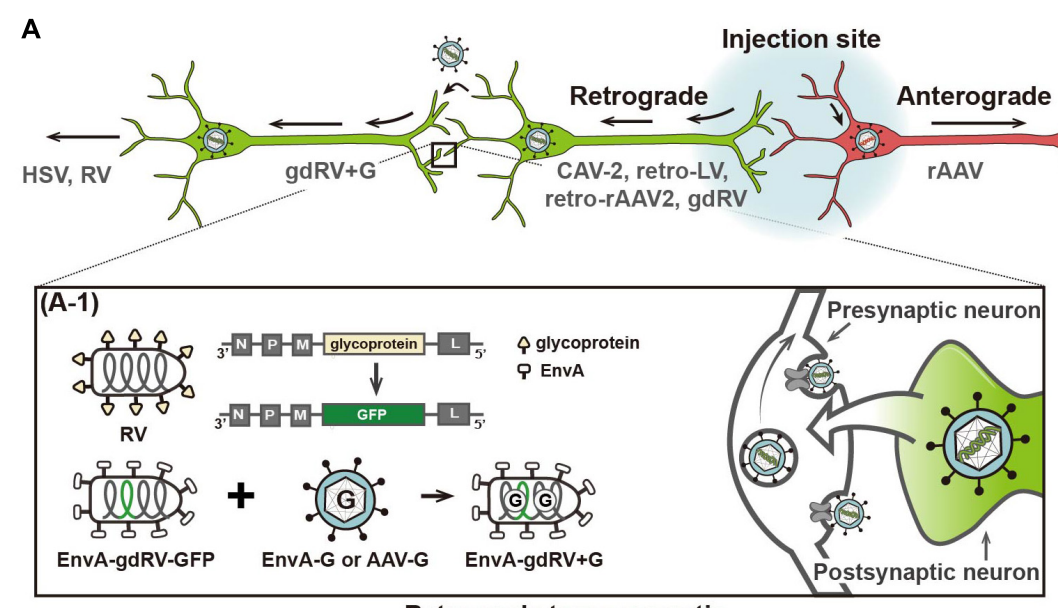

Retrograde trans-synaptic

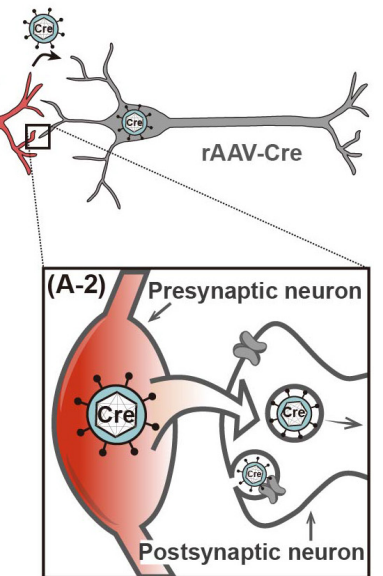

Anterograde trans-synaptic
B

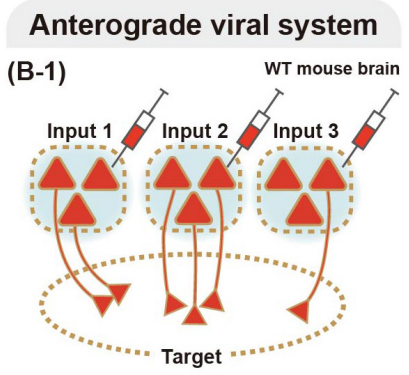

(B-2)

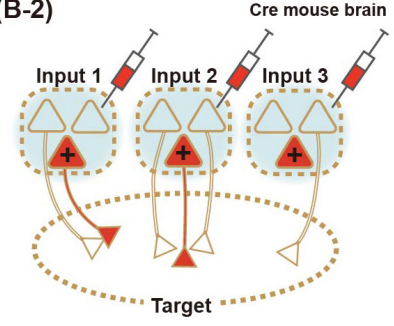

(B-3) WT mouse brain

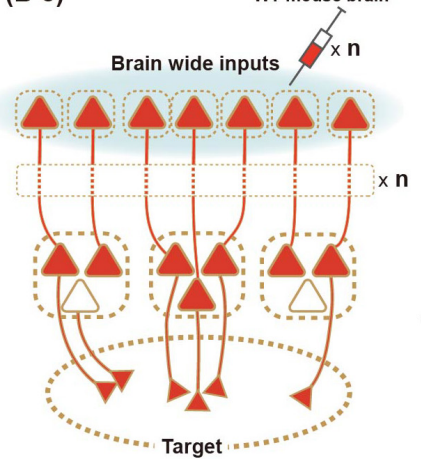

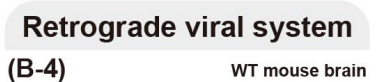

(B-4)

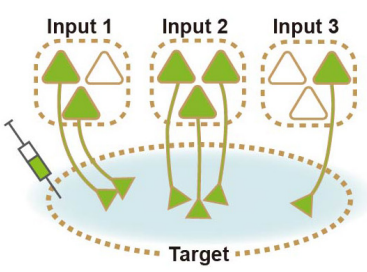

(B-5)

Cre mouse brain

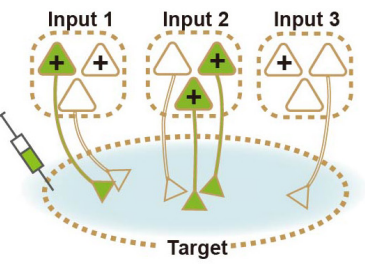

(B-6)

WT mouse brain

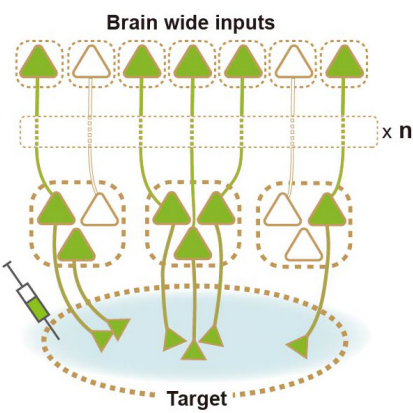

\section{RV-based mono-synpatic viral system}

(B-7)

Cre mouse brain

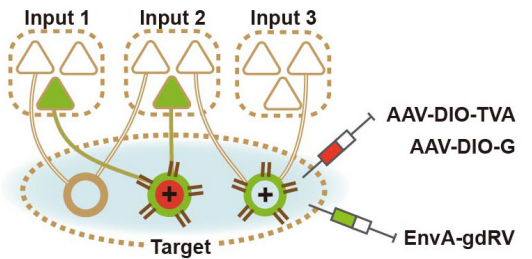

(B-8)

Double floxed inverted open reading frame (DIO)

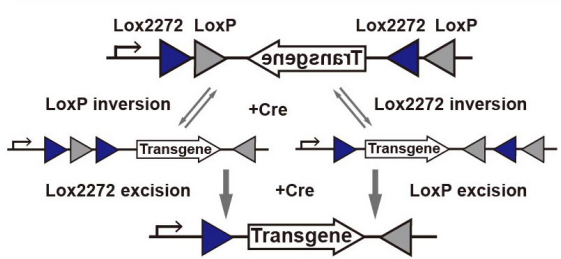

(B-9)

Single floxed open reading frame $(\mathrm{Jx}-\mathrm{ON})$

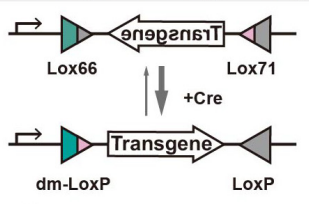

Injection site
Target area
Input area
Cre expressing neurons
Anterograde virus expressing neurons
Retrograde virus expressing neurons

FIGURE 1 | Viral systems for visualizing input convergent circuitry and delivering genetic tools for functional input mapping. (A) Schematic illustration of antero-, retrograde, and transsynaptic viral tracers. Anterograde virus (red) and retrograde virus (green) are distinguished by their neural entry site and axonal transport directions. Several viruses can cross synapse(s) and enter the connected neurons. Transsynaptic delivery of retrograde virus and engineered rabies virus, as an example of trans-synaptic retrograde viral tracers, are illustrated (A-1). Anterograde transsynaptic delivery of AAV 1 or 9 expressing Cre is illustrated (A-2).

(B) Schematic illustration of labeling strategies of various viral systems. For convergence circuit mapping, anterograde virus to the multiple input areas (B-1-3) or retrograde virus to a target area (B-4-6) can be injected. Engineered rabies virus (RV) labels convergent circuits to the cell type neuron in the target area (B-7). Furthermore, antero- and retrograde polysynaptic viruses enable identifying neural circuitries integrated cross multiple synapses by injecting input and target areas, respectively (B-3,6). Two schematic strategies of Cre-dependent viral vectors for labeling particular cell types, such as Double floxed inverted open reading frame $(\mathrm{DIO})$ and single floxed version (Jx-ON) (B-8,9). 
(Zingg et al., 2017, 2020). It has been demonstrated that rAAV can label trans-synaptic outputs via anterograde trans-synaptic transduction when packaged with serotype 1 and 9. AAVmediated trans-synaptic labeling is restricted to Cre expression, and not other proteins of a similar size such as GFP, offering a faithful complementary set of tools for labeling trans-synaptic outputs. Its successful applications have been increasing in inputdefined circuitry functions, such as cortico-collicular pathways for defense behaviors and motion discrimination (Zingg et al., 2017; Beltramo and Scanziani, 2019), and gustatory corticoamygdala pathways for taste (Wang et al., 2018).

\section{Cell Type-Specific Structure Mapping by Anterograde Viral Systems}

Diverse cell types are believed to be responsible for specific functions in a given brain area. Thus, cell type-resolved connectivity profiling will undoubtedly provide novel insights into structural and functional organization of neural networks. Significant progress in classifying diverse neuronal cell types has been made through the development of new techniques, such as single cell RNA sequencing-based molecular profiling, and remains ongoing (Zeng and Sanes, 2017; Luo et al., 2018). Meanwhile, decades-long efforts together with advances in genomics and genetics have generated a useful resource of genetic switch driven lines (mainly Cre) in a cell type-specific manner (Gong et al., 2007; Gerfen et al., 2013; Harris et al., 2014). The rich collection of diverse Cre driver lines have made neuroscience research more efficient and precise, allowing cell type-specific labeling, monitoring, and manipulating. With respect to molecular identity, using these Cre driver lines, AAV engineered for Cre-dependent on/off switching modes has been widely used for selective labeling of a given neuronal type in a given brain area, such as projection pattern- and cortical layer-specific neurons. In the GENSAT collection ${ }^{2}$ for instance, two specific Cre drivers (Tlx3_PL56 and Sim1_KJ18) allow selective labeling of intra-telencephalic (IT)-type and pyramidal tract (PT)-type neurons by injection of AAV expressing Credependent FPs in various sites of the sensory, motor, and frontal cortices (Hooks et al., 2018). This study revealed different topographic organization of cortico-striatal projections of ITand PT-type neurons, suggesting that striatal regions integrate input convergence from multiple cortical areas via at least two different cell type-specific channels. Furthermore, using 49 different Cre driver lines to selectively label cell types in cortical layers showing different projection patterns, cortical cell typespecific connectivity mapping revealed hierarchically organized convergence in the thalamus (Harris et al., 2019).

\section{Structural Input Convergence Mapping With Retrograde Viral Tracers}

Brain-wide mapping of multiple inputs converged into a given target area became evidently feasible and beneficial by collecting comprehensive information from individual datasets using anterograde virus data together with computational

${ }^{2}$ http://www.gensat.org processing, as described above. However, anterograde virusbased convergence mapping can be incomplete, unless all multiple input areas and cell types are covered by viral labeling. Additionally, this approach requires careful validation because of potential misinformation delivered by ectopic injection of the anterograde tracer in neighboring and/or boundary regions around a given input area. Therefore, retrograde axonal transport of tracers, e.g., cholera toxin subunit B and rabies virus (RV), offers considerable advantages to selectively map multiple inputs to a subpopulation of neurons and even to a single neuron (Ugolini et al., 1987; Ugolini, 1995; Lanciego and Wouterlood, 2011; Zingg et al., 2014; Callaway and Luo, 2015; Junyent and Kremer, 2015; Tervo et al., 2016; Mandelbaum et al., 2019; Schwarz and Remy, 2019). In the past decade, there have been advances in developing and improving tools of retrograde viral systems for selective and precise input mapping. Again, several reviews have extensively covered the limitations of conventional non-viral retrograde tracers (Nassi et al., 2015; Saleeba et al., 2019).

\section{Retrograde Viral Systems}

Several types of virus, such as herpes simplex virus (HSV), canine adenovirus-2, and RV, are characterized by retrograde neurotropism through entry at axonal terminals followed by transport to cell bodies. With further engineering, retrograde viral systems have become a valuable tool for dissecting the structural and functional connectivity of various circuits (Norgren and Lehman, 1998; Soudais et al., 2003; Osakada et al., 2011; Kato et al., 2014; Kim E.J. et al., 2016; Tervo et al., 2016; Del Rio et al., 2019). Of these, the RV-based system offers specific retrograde access to mono-synaptically connected neurons to cell(s) in a brain region of interest (Wickersham et al., 2007b). $\mathrm{RV}$ is enveloped by a glycoprotein that mediates retrograde travel between synaptically connected neurons, possibly via multisynaptic jumps. This feature makes it ambiguous to define directly connected pairs of neuronal populations. To construct a trans-synaptic tracer that travels retrogradely by only one synaptic step, a genetically engineered RV system has been developed (Mebatsion et al., 1996; Etessami et al., 2000; Barnard et al., 2006; Wickersham et al., 2007a,b). Glycoprotein-deleted $\mathrm{RV}$ (gdRV) is packaged with the envelope protein of avian sarcoma and leukosis virus (EnvA) to direct its entrance into so-called starter cells expressing avian tumor virus receptor A (TVA). EnvA-packaged gdRV is co-delivered to starter cells with a complementary virus expressing RV glycoprotein (e.g., $A A V-G)$. In the starter cells, gdRV is further packaged with complementarity provided RV glycoprotein, and consequently spreads to presynaptic neurons by only one synaptic step. The engineered RV allows labeling of monosynaptic inputs to the starter cells in a cell type-specific manner-for instance, using Cre drivers and Cre-dependent strategies for expressing TVA (Wall et al., 2010). Given its advantages, such as unambiguous identification of synaptically connected neurons, RV-based systems have been increasingly used for structural and functional mapping of multiple inputs converging from various areas or cell types (Osakada et al., 2011; Dorocic et al., 2014; Sun et al., 2014, 2019; Tian et al., 2016; Ährlund-Richter et al., 2019; 
Lazaridis et al., 2019; Tasaka et al., 2020), as reviewed below. Owing to innate features of rabies virus system, cytotoxicity of rabies infection remains concerning in longer expression (Schnell et al., 2010; Callaway and Luo, 2015) and further effort to reduce its cytotoxicity is in progress (Reardon et al., 2016).

Alternatively, anterograde viral systems have been engineered for implementing a retrograde feature, while keeping their advantages such as a low immune response post-infection, low cytotoxicity, and stability. By engineering retrograde viral glycoproteins for pseudotyping (i.e., RV- and vesicular stomatitis virus-glycoprotein), variants of retrograde lentivirus (LV) have been developed and successfully applied in several animal models (Kato et al., 2011; Kato and Kobayashi, 2020). Using engineered retrograde $L V$, a recent study revealed action selection-related functions of the thalamo-striatal circuit in mice (Kato et al., 2018), and cognitive functions of prefrontal cortex networks in macaque monkeys (Oguchi et al., 2015).

Recently, as one of the most widely used and effective gene delivery systems, rAAV has been engineered for retrograde transport. Retrogradely accessible AAV, named rAAV2-retro, has been engineered by in vivo directed-evolution (Tervo et al., 2016), which is unlike intellectually designed strategies for retrograde LV pseudotyped with naturally existing retrogradely transportable glycoprotein. First, AAV vector libraries were constructed by packaging with engineered capsid variants generated by errorprone PCR, peptide insertion, randomization of loop regions, and DNA shuffling from wild-type capsid genes of variant serotypes. These virus libraries were then pooled and injected into the substantia nigra pars reticulata or cerebellum. Subsequently, spatially remote retrograde target tissues (such as the striatum or hindbrain, respectively) were collected and viral genomes extracted to select virions that had retrogradely reached these areas. Selected capsid sequences were re-cloned for the next AAV library that was subsequently evolved through iterative selection rounds. The final selected variant, rAAV2-retro, showed efficient retrograde access to projection neurons and sufficient expression of genetic tools, such as calcium sensors, for interrogations of structural and functional circuits. As cytotoxicity of RV remains an issue, rAAV2-retro provides promising potential and has been increasingly applied for various studies (Shang et al., 2019; Chen et al., 2020; Cushnie et al., 2020; Lafferty et al., 2020). More recently, another rAAV capsids have been engineered for retrograde transport (Davidsson et al., 2019; Düring et al., 2020). Davidsson et al. (2019) developed a method for capsid engineering, called barcode rational AAV vector evolution (BRAVE) combining rational design and direct evolution. New capsid variants (such as MNM004 and MNM008) generated by BRAVE have been demonstrated as a powerful tool for structural and functional connectivity studies. Düring et al. (2020) constructed self-complementary AAV-DJ/9 for retrograde transport in songbirds and mice by engineering the heparin binding domain that is important for cellular entry of virus (Grimm et al., 2008; Düring et al., 2020). Interestingly, these new engineered capsid variants show retrograde specific access to dopaminergic circuitry, which provides potential for not only various dopaminergic pathway-related studies but also clinical application.

\section{Cell Type-Specific Structure Mapping by Retrograde Viral Systems}

Similar to cell type-specific input mapping based on anterograde viral systems, retrograde viral tracers combined with genetic switch systems enable more detailed information of cell typespecific convergence connectivity. Sun et al. (2019) developed the Cre-dependent TVA-expressing mouse combined with the engineered monosynaptic-RV system to map synaptic inputs to specific cell types in the hippocampal CA1 region of TVAexpressing mice crossed with Cre drivers (CamK2a-, PV-, SOM-, and Dlx5/6-Cre for labeling excitatory pyramidal neurons, parvalbumin $(+)$, somatostatin $(+)$, and general interneurons, respectively). Additionally, recent studies described brain-wide mapping of mono-synaptically connected long-range inputs to different cell types of the medial prefrontal cortex using a Cre-dependent RV system with different interneuron-specific Cre drivers (PV-, SOM-, and VIP-Cre) (Ährlund-Richter et al., 2019; Sun et al., 2019). In Sun et al. (2019), RV-labeled input cells were further identified by immunostaining with several cell type markers, for example, cholinergic and serotonergic neurons. Similarly, another recent study described whole-brain mapping of glutamatergic inputs to the lateral habenula ( $\mathrm{LHb}$ ), and further identified RV-labeled input cell types by single nucleus RNA sequencing (snRNA-seq) (Lazaridis et al., 2019). To define glutamatergic inputs into the LHb, Cre-dependent gdRV-expressing EGFP was injected into the LHb of a vesicular glutamate transporter type 2 (vGluT2) Cre-line. LHb-projecting glutamatergic neurons in the globus pallidus internal segment and lateral hypothalamic area (LHA) were profiled by molecular analysis in terms of gene expression for GABA/glutamate coreleasing components as well as other cell markers. This study revealed that the glutamatergic LHA-LHb circuit is a critical node in value processing, with further functional assessments using activity actuators and sensors, which we review below. Furthermore, combinatorial anterograde and retrograde viral systems enable integration of cell type-specific inputs and target mapping (Dorocic et al., 2014).

\section{Functional Input Convergence Mapping With Activity Actuators and Sensors}

So far, we have described antero- and retrograde viral systems expressing mainly FPs to visualize convergence of structural inputs. Combined with another set of genetically encoded tools for monitoring and manipulating neural activity, these useful viral systems have been applied to interrogate the functional significance of input convergence. Beginning with a brief technical account of recently developed manipulators and sensors of neural activity, we will review recent studies describing their combinatorial applications for physiological and behavioral studies as network-level phenomena (Figure 2).

\section{Activity Actuators: Opto- and Chemo-Genetics}

To dissect circuit functions underlying complex behaviors and various neurological diseases, an obvious approach is perturbation of neural activity in a specified circuit; this was traditionally performed by lesion studies and electrical stimulation. Through perturbation-triggered physiological, 
A

Optogenetics
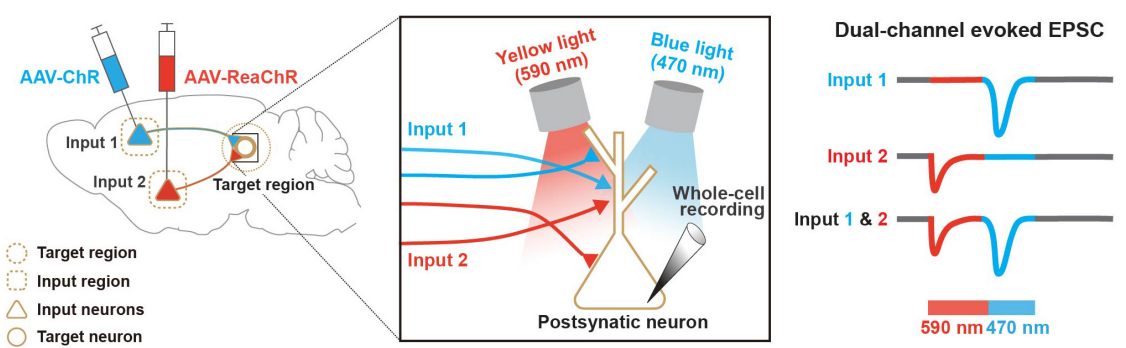

B

Chemogenetics

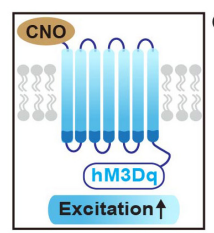

Cre-dependent hM3Dq

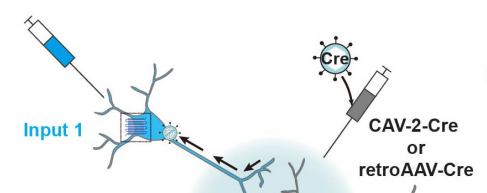

Electrophysiological recording
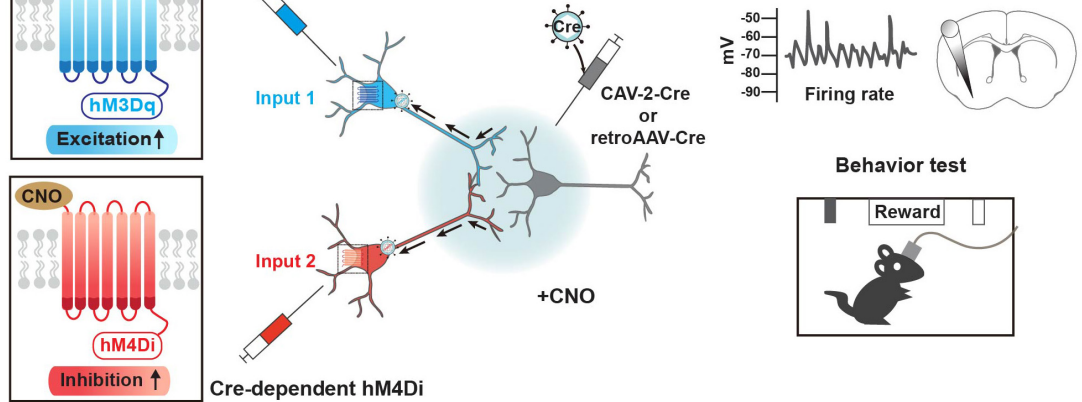

Behavior test

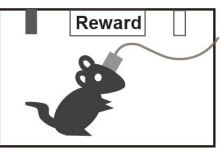

\section{Multi-color XCaMPs}

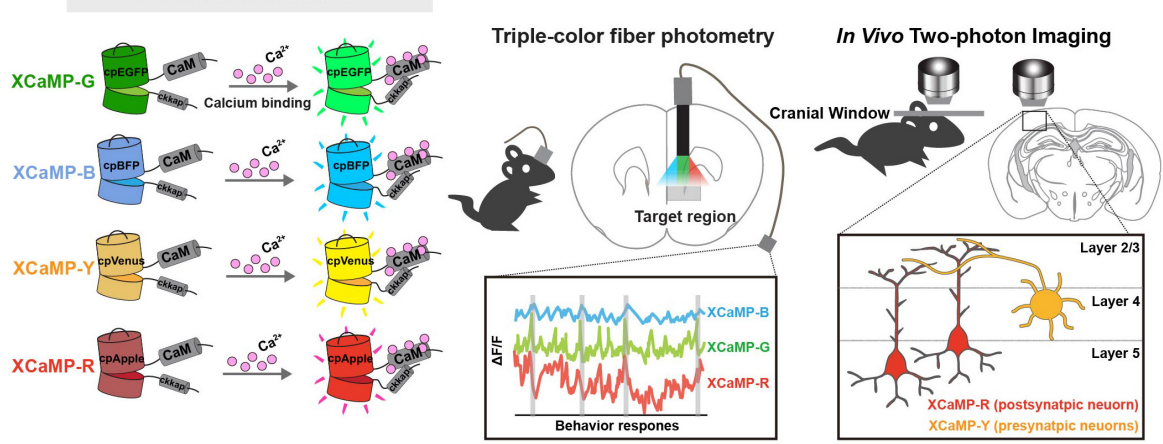

D

Multi-color GETIs
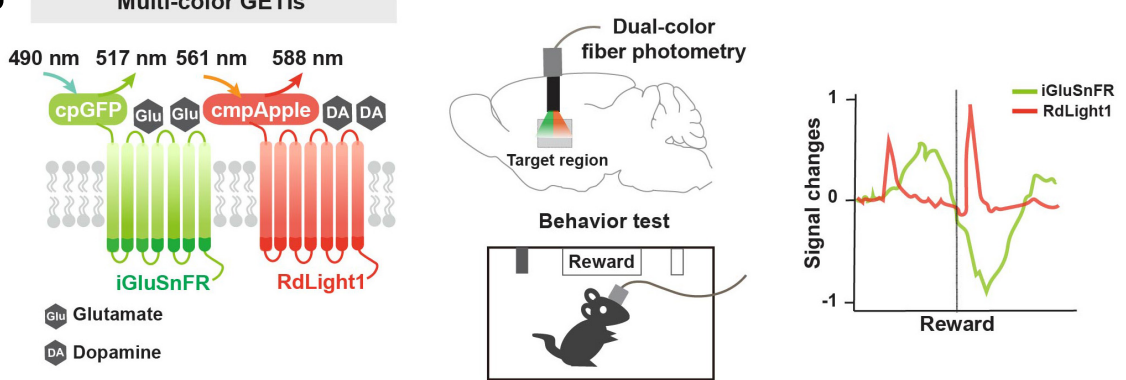

FIGURE 2 | Genetic tools for functional input convergence mapping. (A) Schematic illustration of dual-channel ChR-assisted circuit mapping (2CRAM). AAV expressing ChR2 and ReaChR are injected in different input regions/cell types and postsynaptic target cell recording after illumination (sequential stimulation of 590 and $470 \mathrm{~nm}$ lights) represents functional convergence. (B) Combinatorial strategy of DREADD and retrograde virus for input-selective manipulation. Input neurons are labeled with retrogradely delivered Cre using CAV-2 or retroAAV virus and Cre-dependent DREADDs (e.g., hM3Dq and hM4Di). Electrophysiological recording or behavioral analysis (e.g., reward seeking) after CNO ligand administration represents functional convergence. (C) Illustration of multi-color GECls for convergent circuit mapping. Multi-color GECls (XCaMP-G, -B, -Y, and -R) consist of a circularly permuted FPs and enable to monitor different cell-type activities in the target region of the freely behaving mice. Dual-color imaging for XCaMP-labeled pre- and postsynaptic neurons at a target region represents convergent circuit.

(D) Illustration of multi-color GETIs for convergent circuit mapping. Dual-color imaging for co-expressing iGluSnFR and RdLight1 at the target region enable to monitor glutamate and dopamine releases during behavior test (e.g., reward seeking). 
developmental, and behavioral alterations, potential causality between neural activity of specific circuits with brain functions and behaviors have been discovered. In past years, great advances have been made in manipulating neural activity at specific and precise spatiotemporal resolution using e.g., light- and chemical-controllable genetic tools (i.e., opto- and chemogenetics, respectively). This has led to advances in circuit-level understanding of brain functions and diseases (Kim et al., 2017; Atasoy and Sternson, 2018).

Optogenetic approaches are based on light-sensitive microbial opsins, and enable activation and inactivation of neuronal activity by illumination that opens light-gated ion channels (Boyden et al., 2005; Zhang et al., 2007; Chow et al., 2010; Deisseroth, 2015). Early optogenetic molecules included channelrhodopsin-2 (ChR2) for activation and halorhodopsin for inhibition (Boyden et al., 2005; Zhang et al., 2007). ChR2 is a blue light-gated cation channel conducting $\mathrm{H}^{+}, \mathrm{Na}^{+}, \mathrm{K}^{+}$, and $\mathrm{Ca}^{2+}$ ions, and enabling action potential elicitation. Alternatively, halorhodopsin is a yellow light-gated chloride pump that enables membrane hyperpolarization. These optogentic tools can be delivered into a certain circuit or cell type (mostly by viral gene delivery), and then activated by a small and lightweight implanted fiber-optic probe (Adamantidis et al., 2007; Aravanis et al., 2007; Atasoy et al., 2008; Kuhlman and Huang, 2008), which is connected to a laser diode or light-emitting diode (LED) light source of different wavelengths. Further engineering generated variants of optogenetic tools in terms of light sensitivity, kinetics, functional stability, and so forth. Of the new opsins, red-shifted optogenetic variants (e.g., Crimson and Red-activable [ReaChR]) enable activation of neuronal populations by red light illumination (Zhang et al., 2008; Lin et al., 2013; Klapoetke et al., 2014), and offer the potential to explore circuitry functions of distinct neuronal populations by combinatorial yet specific excitations. In fact, a combinatorial strategy using ChR2 and ReaChR (named 2channel ChR-assisted circuit mapping [2CRACM]) has been used for mapping functional convergence of multiple inputs from the primary somatosensory cortex and posterior medial thalamus on the primary motor cortex (Hooks et al., 2015; Prasad et al., 2020).

As a powerful chemo-genetic approach, designer receptor exclusively activated by designer drug (DREADD), is based on engineered ligand-sensitive receptors and an exogenous ligand specific for these receptors to in/activate neural activity (Sternson and Roth, 2014; Roth, 2016). DREADD utilizes engineered G protein-coupled receptors (GPCR) that respond exclusively to synthetic exogenous chemicals as a ligand, but not to their natural endogenous ligands. With a choice of Gq- and Gi-coupled GPCRs, DREADD can trigger activation and inactivation, respectively, of neuronal activity via intracellular signaling cascades. Similar to optogenetic tools, variants of DREADD have been developed e.g., mutated muscarinic acetylcholine (hM3Dq and hM4Di for activation and inactivation, respectively, by clozapine-N-oxide) and $\kappa$-opioid receptors (KORDi for inactivation of neuronal activity by salvinorin B) (Armbruster et al., 2007; Alexander et al., 2009; Vardy et al., 2015). In particular, a recent study demonstrated that two DREADD variants activated by different ligands, such as KORDi and hM3Dq, enable modulation of neuronal activity and further behaviors (Benekareddy et al., 2018). In parallel, improvement and development of new ligands with greater specificity and less potential side effects are underway. Compared with optogenetics, DREADD-based manipulation has pros and cons: (1) time; optogenetics offers high and precise temporal resolution (on the millisecond-scale), while DREADD-based manipulation is not elicited immediately and is prolonged (on the hour-scale). Nevertheless, this prolonged activation period by DREADD can be beneficial for behavioral and disease models. Furthermore, (2) invasiveness; DREADD offers a less invasive option and is more flexible with simple injection of ligands, while the optogenetic approach requires an implanted intracranial light source. Yet these neuronal activity actuators have become one of the most powerful tools for functional studies of various circuits (Smith et al., 2016; Campbell and Marchant, 2018; Luo et al., 2018; Lee et al., 2020). Moreover, various combinatorial strategies of optogenetics, DREADD, engineered viral systems, and cell type-specific Cre drivers have been designed and successfully applied for investigating functional convergence (Kato et al., 2018; Johansson and Silberberg, 2020; Lafferty et al., 2020; Prasad et al., 2020; Soden et al., 2020; Yamawaki et al., 2020; Zolnik et al., 2020).

\section{Activity Sensors: GECI and GETI}

Monitoring neuronal activity and synaptic events with precise spatiotemporal resolution is necessary to decipher functional information processing engaged in complex behaviors and malfunctioned states of neurological disorders. Development and refinement of genetically encoded sensors will permit better understanding of how neuronal dynamics is encoded in which neural circuits to control brain functions.

Regarding activity sensors (Lin and Schnitzer, 2016), genetically encoded calcium indicators (GECIs) provide the most mature modality for monitoring neural activity. As neural activity causes rapid changes in intracellular $\mathrm{Ca}^{2+}$ level, GECIs have advanced our knowledge of functional circuits (Broussard et al., 2014). GCaMP, the most enthusiastically used GECI, is an intracellular $\mathrm{Ca}^{2+}$ indicator comprising a circularly permuted FP (cpFP, typically cpGFP), $\mathrm{Ca}^{2+}$-binding protein calmodulin (CaM), and a $\mathrm{Ca}^{2+} / \mathrm{CaM}$-sensing domain (typically, M13). Earlier GECI versions are based on Forster resonance energy transfer (FRET) of paired FPs. Single FP-based engineering has virtually revolutionized development of biosensors with sufficient brightness for in vivo events. In the presence of calcium, bright fluorescence can be detected through conformational changes triggered by $\mathrm{Ca}^{2+}$ binding to CaM, with poor fluorescence in the absence of calcium. GCaMP has evolved by engineering its variants to enhance the signal-to-noise ratio, sensitivity, and kinetics (Nakai et al., 2001; Tallini et al., 2006; Tian et al., 2009; Akerboom et al., 2009, 2012; Muto et al., 2011; Chen et al., 2013; Sun et al., 2013; Dana et al., 2016). Additionally, similar to the activity actuators described above, understanding of complex activity dynamics of convergent circuits demands multicolor availability of GECIs. Accordingly, recent efforts have succeeded in providing various colored GECIs that are applicable in vivo, including R-CaMP2, jRGECO1a, and XCaMP-Blue, 
-Yellow, and -Red (Zhao et al., 2011; Inoue et al., 2015, 2019; Dana et al., 2016).

Multicolor availability of GECIs has enabled simultaneous monitoring of neuronal activity of postsynaptic compartments innervated by multiple cell type-specific presynaptic neurons (Inoue et al., 2019). More recently, another expanded endeavor has developed genetically encoded indicators for imaging the release of specific neurotransmitters and neuromodulators. Inspired by the successful application of cpFP in the GCaMP family, various genetically encoded transmitter indicators (GETIs) have been developed using engineered ligand-binding proteins fused with cpFP that is conformationally changed upon binding of glutamate, GABA, acetylcholine, serotonin, and dopamine: iGluSnFR, iGABASnFR, GACh, iSeroSnFR, and dLight, respectively (Marvin et al., 2013, 2019; Jing et al., 2018; Patriarchi et al., 2018; Unger et al., 2020). Again, further development of color variants as well as optimization are ongoing (Wu et al., 2018; Patriarchi et al., 2020). GETIs can importantly dissect neural activity by detecting the release of various neurotransmitters and neuromodulators. Recent studies have demonstrated that application of multicolor GETIs combined with ChR2 and GECI can increase understanding of the functions and mechanisms of complex neural circuitry by mapping input convergence (Patriarchi et al., 2018, 2020; Kazemipour et al., 2019; Lee et al., 2021).

\section{Functional Input Convergence Mapping With Combinatorial Labeling Tools}

A large variety of the powerful tools described above have enriched the neuroscientific arsenal by their combinatorial applications. Today strategies for labeling and defining a specific neuronal population underlying specific behavioral functions has become possible, yet increasingly complex, sophisticated, and representational. Combining active cell labeling, retrograde $\mathrm{RV}$, and DREADD, a recent study revealed that the temporal association cortex (TeA) receives monosynaptic multiple inputs converging from cortical and subcortical areas, playing a critical role in auditory-driven maternal preference for pup calls (Tasaka et al., 2020). In this study, neuronal populations active in response to ultrasonic vocalizations (USVs) were determined by targeted recombination in active populations (TRAP), which is designed to express inducible Cre (CreERT2) under a control of an immediate early gene, such as Fos (Guenthner et al., 2013). Further combination of TRAP and RV allowed visualization of functional input connectivity by introducing RV specifically into TRAPed USV-responsive neurons of the TeA as starter cells. DREADD expression in these USV-TRAP neurons of the TeA demonstrated their functional link to a maternal behavioral effect.

In another recent study, Gong et al. (2020) demonstrated a clever and complex combinatorial strategy for convergence of feeding and drinking circuits, taking advantage of various advanced technologies, i.e., anterograde polysynaptic HSV, Fosmapping, image segmentation using the standardized Allen Brain Atlas, optogenetics, and GECI. The recombinant H129 strain of HSV, a cell type-targetable version, has been demonstrated as an effective anterograde trans-synaptic viral tracer for labeling poly-synaptically connected output cells in cell typespecific Cre lines (Lo and Anderson, 2011). To broadly and unbiasedly search for a convergence hub-type region of feeding and drinking circuits, anterograde polysynaptic HSV was introduced into defined hunger-and-thirst-related neurons, such as Agouti-related protein (AGRP) neurons in the hypothalamic arcuate nucleus (ARC) and nitric oxide synthase 1 (Nos1) in the suprafornical organ (SFO). In addition to identifying active downstream areas engaged in hunger and thirst, Fosimmunostaining was performed after ontogenetic stimulation of these defined hunger-and-thirst-related neurons. The two datasets of cell type-specific HSV and Fos labeling were processed using the Allen Reference Brain for identifying hotspot areas as a convergence point. This intention map of HSV and Fos labeling guided further functional investigations which identified glutamatergic neurons in the peri-locus coeruleus as a polysynaptic convergence hub for hunger and thirst circuits.

\section{Convergence Mapping at the Synapse Level}

Thus far, we have described various advanced tools for mapping structural and functional input convergence, mainly at the regional and cellular levels. Because the synapse is the primary unit of information processing, detailed synapselevel descriptions of connectivity converging from multiple individual neurons has strengthened our understanding of finescale organization of synaptic input profiles governing global and subcellular signal computations.

Electron microscopy (EM)-based dense mapping, with significant recent advances in large-scale image data acquisition and $3 \mathrm{D}$ volume reconstruction, allows visualization of relatively complete neuronal structures, offering high resolution on the nanometer ultrastructure scale (Briggman et al., 2011; Helmstaedter et al., 2013; Morgan et al., 2016; Schmidt et al., 2017; Motta et al., 2019). In recent studies, a combination of two-photon calcium imaging, optogenetics, and EM-based reconstruction permitted synapse-level functional convergence mapping (Bock et al., 2011; Briggman et al., 2011; Lee et al., 2016; Liang et al., 2018; Borges-Merjane et al., 2020). One such study used GECI, such as GCaMP6, to monitor the activity of retina ganglia cell (RGC) axons and dorsolateral geniculate nucleus (dLGN) neurons upon visual stimulation. This was followed by 3D EM reconstruction of dLGN dendrites innervated by RCG axonal boutons (Liang et al., 2018). Liang et al. (2018) demonstrated that clusters of boutons from different RGC axons on dLGN dendrites share similar visual feature preferences, and that one RGC axon can innervate multiple bouton clusters specialized for different visual feature preferences. As it is believed that dendritic signal processing is facilitated by spatially and temporally organized synaptic input patterns such as clustering (Baden et al., 2016; Gökçe et al., 2016; Wilson et al., 2016; Rompani et al., 2017), these results provide important details about the functional implication of fine-scale convergence for the transmission and integration of visual information from the retina to thalamus. 
Additionally, recent studies have described fine-scale distributions of excitatory and inhibitory synaptic input convergence onto individual pyramidal neurons in different cortical layers by EM-based (Karimi et al., 2020) and fluorescent labeling of synaptic component-based 3D reconstruction (Iascone et al., 2020). Iascone et al. (2020) used genetically labeled pre- and post-synaptic components, such as GephyrinEGFP and Homer1c-tdTomato, respectively, as well as annotated spines to map E and I synapses. This study revealed local E/I balance in specific dendritic domains in layer $2 / 3$ cortical neurons that might restrict dendritic and somatic firing. These detailed synaptic mapping studies reveal a precise excitatory/inhibitory balance suggesting distinct principles of signal integration in individual neurons. Using such fluorescent labeling of synaptic components, array tomography (AT) has been developed to visualize synaptic architecture and connection (Micheva and Smith, 2007; Micheva et al., 2010; Collman et al., 2015). AT is a combinatorial method for synaptic composition and connectivity mapping by reconstruction of images of serial ultrathin sections that can be labeled by immunofluorescence and imaged by fluorescence and EM. AT offers detailed synaptic compositions by repeated immunofluorescence labeling of multiple synaptic components.

Alternatively, for synapse-level connectivity mapping, genetically encoded synaptic detectors have been developed, and in particular, GFP reconstitution across synaptic partners (GRASP) technology. These are based on functional complementation between two non-fluorescent split-GFP fragments targeted to the synaptic membranes of the synaptic cleft (Feinberg et al., 2008; Gordon and Scott, 2009). Further variants of GRASP, such as mGRASP, eGRASP, tGRASP, and syb:GRASP, are available for improved accuracy, efficacy, and specificity to detect synapses in complex circuits (Kim et al., 2011; Macpherson et al., 2015; Choi et al., 2018; Shearin et al., 2018). Combination of mGRASP and optogenetics demonstrated that functional measures of synaptic strength correspond strongly with mGRASP-based structural measures of synapse size, which enabled high-resolution functional connection mapping (Song et al., 2018). Similar to the needs for red-shifted ChR and $\mathrm{XCaMP}$, differently colored varieties known as X-RASPs (i.e., yellow Y-RASP and cerulean C-RASP) have been developed. This has broadened their utility to simultaneous labeling of synapses innervated by different inputs conveying distinct

\section{REFERENCES}

Adamantidis, A. R., Zhang, F., Aravanis, A. M., Deisseroth, K., and de Lecea, L. (2007). Neural substrates of awakening probed with optogenetic control of hypocretin neurons. Nature 450, 420-424. doi: 10.1038/nature06310

Ährlund-Richter, S., Xuan, Y., van Lunteren, J. A., Kim, H., Ortiz, C., Pollak Dorocic, I., et al. (2019). A whole-brain atlas of monosynaptic input targeting four different cell types in the medial prefrontal cortex of the mouse. Nat. Neurosci. 22, 657-668. doi: 10.1038/s41593-019-0354-y

Akerboom, J., Chen, T.-W., Wardill, T. J., Tian, L., Marvin, J. S., Mutlu, S., et al. (2012). Optimization of a GCaMP calcium indicator for neural activity imaging. J. Neurosci. 32, 13819-13840. doi: 10.1523/JNEUROSCI.2601-12.2012

Akerboom, J., Rivera, J. D. V., Guilbe, M. M. R., Malavé, E. C. A., Hernandez, H. H., Tian, L., et al. (2009). Crystal structures of the GCaMP calcium sensor reveal the information, for instance, thermo-sensory and visual information (Macpherson et al., 2015) and engram and non-engram (Choi et al., 2018). These GRASP-based approaches can be expanded into multiple synapse-level convergence mapping when limits of color detection are overcome with further optimization and combination in sophisticated strategies.

\section{CONCLUSION AND FUTURE PERSPECTIVES}

In this review, we have described advanced techniques, mainly genetic tools that are currently available for mapping anatomical and functional convergence connectivity. These tools mostly rely on imaging systems and computational platforms that are also in rapid progress (Lichtman et al., 2014; Zong et al., 2017; Kornfeld and Denk, 2018; Skocek et al., 2018; Sych et al., 2019; Wang et al., 2020). Creative and sophisticated combinations of all the above techniques are underway and will go a long way toward allowing untangling complex inputs in neural circuits. Further innovative new technologies are still required, such as less-toxic and definable trans-synaptic viral systems and genetic switches with reversible and spatiotemporally precise on/off control. Continuous upgraded versions of currently available tools and innovations of new tools joined with integrative and combinatorial approaches will provide deeper understanding of how multiple integrative information coordinates a variety of behaviors and cognitions.

\section{AUTHOR CONTRIBUTIONS}

JSY, JK, and JK wrote this manuscript. All authors contributed to the article and approved the submitted version.

\section{FUNDING}

This work was supported by the Korea Institute of Science and Technology (KIST) Institutional Program, Republic of Korea (2E30970), and National Research Foundation of Korea (NRF) grant funded by the Korea Government (MSIP) (2019M3E5D2A01063794).

mechanism of fluorescence signal change and aid rational design. J. Biol. Chem. 284, 6455-6464. doi: 10.1074/jbc.M807657200

Alexander, G. M., Rogan, S. C., Abbas, A. I., Armbruster, B. N., Pei, Y., Allen, J. A., et al. (2009). Remote control of neuronal activity in transgenic mice expressing evolved G protein-coupled receptors. Neuron 63, 27-39. doi: 10.1016/j.neuron. 2009.06.014

Aravanis, A. M., Wang, L.-P., Zhang, F., Meltzer, L. A., Mogri, M. Z., Schneider, M. B., et al. (2007). An optical neural interface: in vivo control of rodent motor cortex with integrated fiberoptic and optogenetic technology. J. Neural Eng. 4, S143-S156. doi: 10.1088/1741-2560/4/3/S02

Armbruster, B. N., Li, X., Pausch, M. H., Herlitze, S., and Roth, B. L. (2007). Evolving the lock to fit the key to create a family of $G$ protein-coupled receptors potently activated by an inert ligand. Proc. Natl. Acad. Sci. U.S.A. 104, 5163-5168. doi: 10.1073/pnas.0700293104 
Atasoy, D., Aponte, Y., Su, H. H., and Sternson, S. M. (2008). A FLEX switch targets channelrhodopsin-2 to multiple cell types for imaging and long-range circuit mapping. J. Neurosci. 28, 7025-7030. doi: -0.1523/JNEUROSCI.1954-08.2008

Atasoy, D., and Sternson, S. M. (2018). Chemogenetic tools for causal cellular and neuronal biology. Physiol. Rev. 98, 391-418. doi: 10.1152/physrev.00009.2017

Baden, T., Berens, P., Franke, K., Rosón, M. R., Bethge, M., and Euler, T. (2016). The functional diversity of retinal ganglion cells in the mouse. Nature 529, 345-350. doi: 10.1038/nature16468

Barnard, R. J. O., Elleder, D., and Young, J. A. T. (2006). Avian sarcoma and leukosis virus-receptor interactions: from classical genetics to novel insights into virus cell membrane fusion. Virology 344, 25-29. doi: 10.1016/j.virol.2005.09.021

Beltramo, R., and Scanziani, M. (2019). A collicular visual cortex: neocortical space for an ancient midbrain visual structure. Science 363, 64-69. doi: 10.1126/ science.aau7052

Benekareddy, M., Stachniak, T. J., Bruns, A., Knoflach, F., Kienlin, M., Künnecke, B., et al. (2018). Identification of a corticohabenular circuit regulating socially directed behavior. Biol. Psychiatry 83, 607-617. doi: 10.1016/j.biopsych.2017 .10 .032

Bock, D. D., Lee, W.-C. A., Kerlin, A. M., Andermann, M. L., Hood, G., Wetzel, A. W., et al. (2011). Network anatomy and in vivo physiology of visual cortical neurons. Nature 471, 177-182. doi: 10.1038/nature09802

Borges-Merjane, C., Kim, O., and Jonas, P. (2020). Functional electron microscopy, "Flash and Freeze," of identified cortical synapses in acute brain slices. Neuron 105, 992-1006.e6. doi: 10.1016/j.neuron.2019.12.022

Boyden, E. S., Zhang, F., Bamberg, E., Nagel, G., and Deisseroth, K. (2005). Millisecond-timescale, genetically targeted optical control of neural activity. Nat. Neurosci. 8, 1263-1268. doi: 10.1038/nn1525

Briggman, K. L., Helmstaedter, M., and Denk, W. (2011). Wiring specificity in the direction-selectivity circuit of the retina. Nature 471, 183-188. doi: 10.1038/ nature 09818

Broussard, G. J., Liang, R., and Tian, L. (2014). Monitoring activity in neural circuits with genetically encoded indicators. Front. Mol. Neurosci. 7:97. doi: 10.3389/fnmol.2014.00097

Callaway, E. M., and Luo, L. (2015). Monosynaptic circuit tracing with glycoprotein-deleted rabies viruses. J. Neurosci. 35, 8979-8985. doi: 10.1523/ JNEUROSCI.0409-15.2015

Campbell, E. J., and Marchant, N. J. (2018). The use of chemogenetics in behavioural neuroscience: receptor variants, targeting approaches and caveats. Br. J. Pharmacol. 175, 994-1003. doi: 10.1111/bph.14146

Chen, T. W., Wardill, T. J., Sun, Y., Pulver, S. R., Renninger, S. L., Baohan, A., et al. (2013). Ultrasensitive fluorescent proteins for imaging neuronal activity. Nature 449, 295-300. doi: 10.1038/nature 12354

Chen, Z., Fan, G., Li, A., Yuan, J., and Xu, T. (2020). rAAV2-retro enables extensive and high-efficient transduction of lower motor neurons following intramuscular injection. Mol. Ther. Methods Clin. Dev. 17, 21-33. doi: 10.1016/ j.omtm.2019.11.006

Choi, J.-H., Sim, S.-E., Kim, J.-I., Choi, D. Il, Oh, J., Ye, S., et al. (2018). Interregional synaptic maps among engram cells underlie memory formation. Science 360, 430-435. doi: 10.1126/science.aas9204

Chow, B. Y., Han, X., Dobry, A. S., Qian, X., Chuong, A. S., Li, M., et al. (2010). High-performance genetically targetable optical neural silencing by light-driven proton pumps. Nature 463, 98-102. doi: 10.1038/nature08652

Collman, F., Buchanan, J., Phend, K. D., Micheva, K. D., Weinberg, R. J., and Smith, S. J. (2015). Mapping synapses by conjugate light-electron array tomography. J. Neurosci. 35, 5792-5807. doi: 10.1523/JNEUROSCI.4274-14.2015

Cook, S. J., Jarrell, T. A., Brittin, C. A., Wang, Y., Bloniarz, A. E., Yakovlev, M. A., et al. (2019). Whole-animal connectomes of both Caenorhabditis elegans sexes. Nature 571, 63-71. doi: 10.1038/s41586-019-1352-7

Cui, G., Jun, S. B., Jin, X., Pham, M. D., Vogel, S. S., Lovinger, D. M., et al. (2013). Concurrent activation of striatal direct and indirect pathways during action initiation. Nature 494, 238-242. doi: 10.1038/nature11846

Cushnie, A. K., El-Nahal, H. G., Bohlen, M. O., May, P. J., Basso, M. A., Grimaldi, P., et al. (2020). Using rAAV2-retro in rhesus macaques: Promise and caveats for circuit manipulation. J. Neurosci. Methods 345:108859. doi: 10.1016/j.jneumeth. 2020.108859

Dana, H., Mohar, B., Sun, Y., Narayan, S., Gordus, A., Hasseman, J. P., et al. (2016). Sensitive red protein calcium indicators for imaging neural activity. eLife 5:e12727. doi: 10.7554/eLife.12727
Davidsson, M., Wang, G., Aldrin-Kirk, P., Cardoso, T., Nolbrant, S., Hartnor, M., et al. (2019). A systematic capsid evolution approach performed in vivo for the design of AAV vectors with tailored properties and tropism. Proc. Natl. Acad. Sci. U.S.A. 116, 27053-27062. doi: 10.1073/pnas.1910061116

DeFalco, J., Tomishima, M., Liu, H., Zhao, C., Cai, X., Marth, J. D., et al. (2001). Virus-assisted mapping of neural inputs to a feeding center in the hypothalamus. Science 291, 2608-2613. doi: 10.1126/science.1056602

Deisseroth, K. (2015). Optogenetics: 10 years of microbial opsins in neuroscience. Nat. Neurosci. 18, 1213-1225. doi: 10.1038/nn.4091

Del Rio, D., Beucher, B., Lavigne, M., Wehbi, A., Gonzalez Dopeso-Reyes, I., Saggio, I., et al. (2019). CAV-2 vector development and gene transfer in the central and peripheral nervous systems. Front. Mol. Neurosci. 12:71. doi: 10.3389/fnmol. 2019.00071

Dorocic, I. P., Fürth, D., Xuan, Y., Johansson, Y., Pozzi, L., Silberberg, G., et al. (2014). A whole-brain atlas of inputs to serotonergic neurons of the dorsal and median raphe nuclei. Neuron 83, 663-678. doi: 10.1016/j.neuron.2014.07.002

Druckmann, S., Feng, L., Lee, B., Yook, C., Zhao, T., Magee, J. C., et al. (2014). Structured synaptic connectivity between hippocampal regions. Neuron 81 , 629-640. doi: 10.1016/j.neuron.2013.11.026

Düring, D. N., Dittrich, F., Rocha, M. D., Tachibana, R. O., Mori, C., Okanoya, K., et al. (2020). Fast retrograde access to projection neuron circuits underlying vocal learning in songbirds. Cell Rep. 33:108364. doi: 10.1016/j.celrep.2020. 108364

Etessami, R., Conzelmann, K. K., Fadai-Ghotbi, B., Natelson, B., Tsiang, H., and Ceccaldi, P. E. (2000). Spread and pathogenic characteristics of a G-deficient rabies virus recombinant: An in vitro and in vivo study. J. Gen. Virol. 81, 2147-2153. doi: 10.1099/0022-1317-81-9-2147

Feinberg, E. H., Vanhoven, M. K., Bendesky, A., Wang, G., Fetter, R. D., Shen, K., et al. (2008). GFP Reconstitution across synaptic partners (GRASP) defines cell contacts and synapses in living nervous systems. Neuron 57, 353-363. doi: 10.1016/j.neuron.2007.11.030

Flusberg, B. A., Nimmerjahn, A., Cocker, E. D., Mukamel, E. A., Barretto, R. P. J., Ko, T. H., et al. (2008). High-speed, miniaturized fluorescence microscopy in freely moving mice. Nat. Methods 5, 935-938. doi: 10.1038/nmeth.1256

Gerfen, C. R., Paletzki, R., and Heintz, N. (2013). GENSAT BAC cre-recombinase driver lines to study the functional organization of cerebral cortical and basal ganglia circuits. Neuron 80, 1368-1383. doi: 10.1016/j.neuron.2013.10.016

Ghosh, K. K., Burns, L. D., Cocker, E. D., Nimmerjahn, A., Ziv, Y., Gamal, A. E., et al. (2011). Miniaturized integration of a fluorescence microscope. Nat. Methods 8, 871-878. doi: 10.1038/nmeth.1694

Gökçe, O., Bonhoeffer, T., and Scheuss, V. (2016). Clusters of synaptic inputs on dendrites of layer 5 pyramidal cells in mouse visual cortex. eLife 5:e09222. doi: 10.7554/eLife.09222

Gong, H., Xu, D., Yuan, J., Li, X., Guo, C., Peng, J., et al. (2016). Highthroughput dual-colour precision imaging for brain-wide connectome with cytoarchitectonic landmarks at the cellular level. Nat. Commun. 7:12142. doi: 10.1038/ncomms12142

Gong, R., Xu, S., Hermundstad, A., Yu, Y., and Sternson, S. M. (2020). Hindbrain double-negative feedback mediates palatability-guided food and water consumption. Cell 182, 1589-1605.e22. doi: 10.1016/j.cell.2020. 07.031

Gong, S., Doughty, M., Harbaugh, C. R., Cummins, A., Hatten, M. E., Heintz, N., et al. (2007). Targeting Cre recombinase to specific neuron populations with bacterial artificial chromosome constructs. J. Neurosci. 27, 9817-9823. doi: 10.1523/JNEUROSCI.2707-07.2007

Gordon, M. D., and Scott, K. (2009). Motor control in a drosophila taste circuit. Neuron 61, 373-384. doi: 10.1016/j.neuron.2008.12.033

Gossen, M., and Bujard, H. (1992). Tight control of gene expression in mammalian cells by tetracycline-responsive promoters. Proc. Natl. Acad. Sci. U.S.A. 89, 5547-5551. doi: 10.1073/pnas.89.12.5547

Grimm, D., Lee, J. S., Wang, L., Desai, T., Akache, B., Storm, T. A., et al. (2008). In vitro and in vivo gene therapy vector evolution via multispecies interbreeding and retargeting of adeno-associated viruses. J. Virol. 12, 5887-5911. doi: 10. 1128/JVI.00254-08

Guenthner, C. J., Miyamichi, K., Yang, H. H., Heller, H. C., and Luo, L. (2013). Permanent genetic access to transiently active neurons via TRAP: targeted recombination in active populations. Neuron 78, 773-784. doi: 10.1016/j. neuron.2013.03.025 
Haggerty, D. L., Grecco, G. G., Reeves, K. C., and Atwood, B. (2020). Adenoassociated viral vectors in neuroscience research. Mol. Ther. Methods Clin. Dev. 17, 69-82. doi: 10.1016/j.omtm.2019.11.012

Harris, J. A., Hirokawa, K. E., Sorensen, S. A., Gu, H., Mills, M., Ng, L. L., et al. (2014). Anatomical characterization of Cre driver mice for neural circuit mapping and manipulation. Front. Neural. Circuits 8:76. doi: 10.3389/fncir. 2014.00076

Harris, J. A., Mihalas, S., Hirokawa, K. E., Whitesell, J. D., Choi, H., Bernard, A., et al. (2019). Hierarchical organization of cortical and thalamic connectivity. Nature 575, 195-202. doi: 10.1038/s41586-019-1716-z

Helmstaedter, M., Briggman, K. L., Turaga, S. C., Jain, V., Seung, H. S., and Denk, W. (2013). Connectomic reconstruction of the inner plexiform layer in the mouse retina. Nature 500, 168-174. doi: 10.1038/nature12346

Hildebrand, D. G. C., Cicconet, M., Torres, R. M., Choi, W., Quan, T. M., Moon, J., et al. (2017). Whole-brain serial-section electron microscopy in larval zebrafish. Nature 545, 345-349. doi: 10.1038/nature22356

Hooks, B. M., Lin, J. Y., Guo, C., and Svoboda, K. (2015). Dual-channel circuit mapping reveals sensorimotor convergence in the primary motor cortex. J. Neurosci. 35, 4418-4426. doi: 10.1523/JNEUROSCI.3741-14.2015

Hooks, B. M., Papale, A. E., Paletzki, R. F., Feroze, M. W., Eastwood, B. S., Couey, J. J., et al. (2018). Topographic precision in sensory and motor corticostriatal projections varies across cell type and cortical area. Nat. Commun. 9:3549. doi: 10.1038/s41467-018-05780-7

Hunnicutt, B. J., Jongbloets, B. C., Birdsong, W. T., Gertz, K. J., Zhong, H., and Mao, T. (2016). A comprehensive excitatory input map of the striatum reveals novel functional organization. eLife 5, e19103. doi: 10.7554/eLife.19103

Hunnicutt, B. J., Long, B. R., Kusefoglu, D., Gertz, K. J., Zhong, H., and Mao, T. (2014). A comprehensive thalamocortical projection map at the mesoscopic level. Nat. Neurosci 17, 1276-1285. doi: 10.1038/nn.3780

Iascone, D. M., Li, Y., Sümbül, U., Doron, M., Chen, H., Andreu, V., et al. (2020). Whole-neuron synaptic mapping reveals spatially precise excitatory/inhibitory balance limiting dendritic and somatic spiking. Neuron 106, 566-578.e8. doi: 10.1016/j.neuron.2020.02.015

Inoue, M., Takeuchi, A., Horigane, S.-I., Ohkura, M., Gengyo-Ando, K., Fujii, H., et al. (2015). Rational design of a high-affinity, fast, red calcium indicator R-CaMP2. Nat. Methods 12, 64-70. doi: 10.1038/nmeth.3185

Inoue, M., Takeuchi, A., Manita, S., Horigane, S.-I., Sakamoto, M., Kawakami, R., et al. (2019). Rational engineering of XCaMPs, a multicolor GECI suite for in vivo imaging of complex brain circuit dynamics. Cell 177, 1346-1360.e24. doi: 10.1016/j.cell.2019.04.007

Jing, M., Zhang, P., Wang, G., Feng, J., Mesik, L., Zeng, J., et al. (2018). A genetically encoded fluorescent acetylcholine indicator for in vitro and in vivo studies. Nat. Biotechnol. 36, 726-737. doi: 10.1038/nbt.4184

Johansson, Y., and Silberberg, G. (2020). The functional organization of cortical and thalamic inputs onto five types of striatal neurons is determined by source and target cell identities. Cell Rep. 30, 1178-1194.e3. doi: 10.1016/j.celrep.2019. 12.095

Junyent, F., and Kremer, E. J. (2015). CAV-2 - why a canine virus is a neurobiologist's best friend. Curr. Opin. Pharmacol. 24, 86-93. doi: 10.1016/j. coph.2015.08.004

Karimi, A., Odenthal, J., Drawitsch, F., Boergens, K. M., and Helmstaedter, M. (2020). Cell-type specific innervation of cortical pyramidal cells at their apical dendrites. eLife 9:e46876. doi: 10.7554/eLife.46876

Kasthuri, N., Hayworth, K. J., Berger, D. R., Schalek, R. L., Conchello, J. A., Knowles-Barley, S., et al. (2015). Saturated reconstruction of a volume of neocortex. Cell 162, 648-661. doi: 10.1016/j.cell.2015.06.054

Kato, S., Fukabori, R., Nishizawa, K., Okada, K., Yoshioka, N., Sugawara, M., et al. (2018). Action selection and flexible switching controlled by the intralaminar thalamic neurons. Cell Rep. 22, 2370-2382. doi: 10.1016/j.celrep.2018.02.016

Kato, S., and Kobayashi, K. (2020). Pseudotyped lentiviral vectors for tracttargeting and application for the functional control of selective neural circuits. J. Neurosci. Methods. 344:108854. doi: 10.1016/j.jneumeth.2020.108854

Kato, S., Kobayashi, K., Inoue, K.-I., Kuramochi, M., Okada, T., Yaginuma, H., et al. (2011). A lentiviral strategy for highly efficient retrograde gene transfer by pseudotyping with fusion envelope glycoprotein. Hum. Gene Ther. 22, 197-206. doi: 10.1089/hum.2009.179

Kato, S., Kobayashi, K., and Kobayashi, K. (2014). Improved transduction efficiency of a lentiviral vector for neuron-specific retrograde gene transfer by optimizing the junction of fusion envelope glycoprotein. J. Neurosci. Methods 227, 151-158. doi: 10.1016/j.jneumeth.2014.02.015

Kazemipour, A., Novak, O., Flickinger, D., Marvin, J. S., Abdelfattah, A. S., King, J., et al. (2019). Kilohertz frame-rate two-photon tomography. Nat. Methods 16, 778-786. doi: 10.1038/s41592-019-0493-9

Kim, C. K., Adhikari, A., and Deisseroth, K. (2017). Integration of optogenetics with complementary methodologies in systems neuroscience. Nature 18, 222235. doi: $10.1038 / \mathrm{nrn} .2017 .15$

Kim, C. K., Yang, S. J., Pichamoorthy, N., Young, N. P., Kauvar, I., Jennings, J. H., et al. (2016). Simultaneous fast measurement of circuit dynamics at multiple sites across the mammalian brain. Nat. Methods 13, 325-328. doi: 10.1038/ nmeth. 3770

Kim, E. J., Jacobs, M. W., Ito-Cole, T., and Callaway, E. M. (2016). Improved monosynaptic neural circuit tracing using engineered rabies virus glycoproteins. Cell Rep. 15, 692-699. doi: 10.1016/j.celrep.2016.03.067

Kim, J., Zhao, T., Petralia, R. S., Yu, Y., Peng, H., Myers, E., et al. (2011). mGRASP enables mapping mammalian synaptic connectivity with light microscopy. Nat. Methods 9, 96-102. doi: 10.1038/nmeth.1784

Klapoetke, N. C., Murata, Y., Kim, S. S., Pulver, S. R., Birdsey-Benson, A., Cho, Y. K., et al. (2014). Addendum: independent optical excitation of distinct neural populations. Nat. Methods 11:972. doi: 10.1038/nmeth0914-972

Kornfeld, J., and Denk, W. (2018). Progress and remaining challenges in highthroughput volume electron microscopy. Curr. Opin. Neurobiol. 50, 261-267. doi: $10.1016 /$ j.conb.2018.04.030

Kötter, R. (2004). Online retrieval, processing, and visualization of primate connectivity data from the CoCoMac database. Neuroinformatics 2, 127-144. doi: 10.1385/NI:2:2:127

Kuan, L., Li, Y., Lau, C., Feng, D., Bernard, A., Sunkin, S. M., et al. (2015). Neuroinformatics of the allen mouse brain connectivity atlas. Methods 73, 4-17. doi: 10.1016/j.ymeth.2014.12.013

Kuhlman, S. J., and Huang, Z. J. (2008). High-resolution labeling and functional manipulation of specific neuron types in mouse brain by Cre-activated viral gene expression. PLoS One 3:e2005. doi: 10.1371/journal.pone.0002005

Lafferty, C. K., Yang, A. K., Mendoza, J. A., and Britt, J. P. (2020). Nucleus accumbens cell type- and input-specific suppression of unproductive reward seeking. Cell Rep 30, 3729-3742.e3. doi: 10.1016/j.celrep.2020.02.095

Lanciego, J. L., and Wouterlood, F. G. (2011). A half century of experimental neuroanatomical tracing. J. Chem. Neuroanat. 42, 157-183. doi: 10.1016/j. jchemneu.2011.07.001

Lazaridis, I., Tzortzi, O., Weglage, M., Märtin, A., Xuan, Y., Parent, M., et al. (2019). A hypothalamus-habenula circuit controls aversion. Mol. Psychiatry 24, 1351-1368. doi: 10.1038/s41380-019-0369-5

Lee, C., Lavoie, A., Liu, J., Chen, S. X., and Liu, B.-H. (2020). Light up the brain: the application of optogenetics in cell-type specific dissection of mouse brain circuits. Front. Neural. Circuits 14:18. doi: 10.3389/fncir.2020.00018

Lee, S. J., Lodder, B., Chen, Y., Patriarchi, T., Tian, L., and Sabatini, B. L. (2021). Cell-type-specific asynchronous modulation of PKA by dopamine in learning. Nature 590, 451-456. doi: 10.1038/s41586-020-03050-5

Lee, W.-C. A., Bonin, V., Reed, M., Graham, B. J., Hood, G., Glattfelder, K., et al. (2016). Anatomy and function of an excitatory network in the visual cortex. Nature 532, 370-374. doi: 10.1038/nature17192

Liang, L., Fratzl, A., Goldey, G., Ramesh, R. N., Sugden, A. U., Morgan, J. L., et al. (2018). A fine-scale functional logic to convergence from retina to thalamus. Cell 173, 1343.e1-1343.e24. doi: 10.1016/j.cell.2018.04.041

Lichtman, J. W., Pfister, H., and Shavit, N. (2014). The big data challenges of connectomics. Nat. Neurosci. 17, 1448-1454. doi: 10.1038/nn.3837

Lin, J. Y., Knutsen, P. M., Muller, A., Kleinfeld, D., and Tsien, R. Y. (2013). ReaChR: a red-shifted variant of channelrhodopsin enables deep transcranial optogenetic excitation. Nat. Neurosci. 16, 1499-1508. doi: 10.1038/nn.3502

Lin, M. Z., and Schnitzer, M. J. (2016). Genetically encoded indicators of neuronal activity. Nat. Neurosci. 19, 1142-1153. doi: 10.1038/nn. 4359

Lo, L., and Anderson, D. J. (2011). A Cre-dependent, anterograde transsynaptic viral tracer for mapping output pathways of genetically marked neurons. Neuron 72, 938-950. doi: 10.1016/j.neuron.2011.12.002

Luo, L., Callaway, E. M., and Svoboda, K. (2018). Genetic dissection of neural circuits: a decade of progress. Neuron 98, 256-281. doi: 10.1016/j.neuron.2018. 03.040 
Macpherson, L. J., Zaharieva, E. E., Kearney, P. J., Alpert, M. H., Lin, T.-Y., Turan, Z., et al. (2015). Dynamic labelling of neural connections in multiple colours by trans-synaptic fluorescence complementation. Nat. Commun. 6, 10024-10029. doi: $10.1038 /$ ncomms 10024

Mandelbaum, G., Taranda, J., Haynes, T. M., Hochbaum, D. R., Huang, K. W., Hyun, M., et al. (2019). Distinct cortical-thalamic-striatal circuits through the parafascicular nucleus. Neuron 102, 636.e-652.e. doi: 10.1016/j.neuron.2019.02. 035

Marvin, J. S., Borghuis, B. G., Tian, L., Cichon, J., Harnett, M. T., Akerboom, J., et al. (2013). An optimized fluorescent probe for visualizing glutamate neurotransmission. Nat. Methods 10, 162-170. doi: 10.1038/nmeth.2333

Marvin, J. S., Shimoda, Y., Magloire, V., Leite, M., Kawashima, T., Jensen, T. P., et al. (2019). A genetically encoded fluorescent sensor for in vivo imaging of GABA. Nat. Methods 16, 763-770. doi: 10.1038/s41592-019-0471-2

Mebatsion, T., Konig, M., and Conzelmann, K. K. (1996). Budding of rabies virus particles in the absence of the spike glycoprotein. Cell 84, 941-951. doi: 10.1016/ S0092-8674(00)81072-7

Micheva, K. D., Busse, B., Weiler, N. C., O’Rourke, N., and Smith, S. J. (2010). Single-synapse analysis of a diverse synapse population: proteomic imaging methods and markers. Neuron 68, 639-653. doi: 10.1016/j.neuron.2010.09.024

Micheva, K. D., and Smith, S. J. (2007). Array tomography: a new tool for imaging the molecular architecture and ultrastructure of neural circuits. Neuron 55, 25-36. doi: 10.1016/j.neuron.2007.06.014

Morgan, J. L., Berger, D. R., Wetzel, A. W., and Lichtman, J. W. (2016). The fuzzy logic of network connectivity in mouse visual thalamus. Cell 165, 192-206. doi: 10.1016/j.cell.2016.02.033

Motta, A., Berning, M., Boergens, K. M., Staffler, B., Beining, M., Loomba, S., et al. (2019). Dense connectomic reconstruction in layer 4 of the somatosensory cortex. Science 366, eaay3134. doi: 10.1126/science.aay3134

Muto, A., Ohkura, M., Kotani, T., Higashijima, S., Nakai, J., and Kawakami, K. (2011). Genetic visualization with an improved GCaMP calcium indicator reveals spatiotemporal activation of the spinal motor neurons in zebrafish. Proc. Natl. Acad. Sci. U.S.A 108, 5425-5430. doi: 10.1073/pnas.1000887108

Nakai, J., Ohkura, M., and Imoto, K. (2001). A high signal-to-noise Ca 2+ probe composed of a single green fluorescent protein. Nat. Biotechnol. 19, 137-141. doi: $10.1038 / 84397$

Nassi, J. J., Cepko, C. L., Born, R. T., and Beier, K. T. (2015). Neuroanatomy goes viral! Front. Neuroanat. 9, 80. doi: 10.3389/fnana.2015.00080

Norgren, R. B., and Lehman, M. N. (1998). Herpes simplex virus as a transneuronal tracer. Neurosci. Biobehav. Rev. 22, 695-708. doi: 10.1016/s0149-7634(98) 00008-6

Oguchi, M., Okajima, M., Tanaka, S., Koizumi, M., Kikusui, T., Ichihara, N., et al. (2015). Double virus vector infection to the prefrontal network of the macaque brain. PLoS One 10:e0132825. doi: 10.1371/journal.pone.0132825

Oh, S. W., Harris, J. A., Ng, L., Winslow, B., Cain, N., Mihalas, S., et al. (2014). A mesoscale connectome of the mouse brain. Nature 508, 207-214. doi: 10.1038/ nature 13186

Osakada, F., Mori, T., Cetin, A. H., Marshel, J. H., Virgen, B., and Callaway, E. M. (2011). New rabies virus variants for monitoring and manipulating activity and gene expression in defined neural circuits. Neuron 71, 617-631. doi: 10.1016/j. neuron.2011.07.005

Patriarchi, T., Cho, J. R., Merten, K., Howe, M. W., Marley, A., Xiong, W.-H., et al. (2018). Ultrafast neuronal imaging of dopamine dynamics with designed genetically encoded sensors. Science 360:eaat4422. doi: 10.1126/science.aat 4422

Patriarchi, T., Mohebi, A., Sun, J., Marley, A., Liang, R., Dong, C., et al. (2020). An expanded palette of dopamine sensors for multiplex imaging in vivo. Nat. Methods 17, 1147-1155. doi: 10.1038/s41592-020-0936-3

Prasad, A. A., Xie, C., Chaichim, C., Nguyen, J. H., McClusky, H. E., Killcross, S., et al. (2020). Complementary roles for ventral pallidum cell types and their projections in relapse. J. Neurosci. 40, 880-893. doi: 10.1523/JNEUROSCI.026219.2019

Ragan, T., Kadiri, L. R., Venkataraju, K. U., Bahlmann, K., Sutin, J., Taranda, J., et al. (2012). Serial two-photon tomography for automated ex vivo mouse brain imaging. Nat. Methods 9, 255-258. doi: 10.1038/nmeth.1854

Reardon, T. R., Murray, A. J., Turi, G. F., Wirblich, C., Croce, K. R., Schnell, M. J., et al. (2016). Rabies virus CVS-N2c $(\Delta G)$ strain enhances retrograde synaptic transfer and neuronal viability. Neuron 89, 711-724. doi: 10.1016/j.neuron. 2016.01.004
Rompani, S. B., Müllner, F. E., Wanner, A., Zhang, C., Roth, C. N., Yonehara, K., et al. (2017). Different modes of visual integration in the lateral geniculate nucleus revealed by single-cell-initiated transsynaptic tracing. Neuron 93, 767.e-776.e. doi: 10.1016/j.neuron.2017.01.028

Roth, B. L. (2016). DREADDs for neuroscientists. Neuron 89, 683-694. doi: 10. 1016/j.neuron.2016.01.040

Sabatini, B. L., and Tian, L. (2020). Imaging neurotransmitter and neuromodulator dynamics in vivo with genetically encoded indicators. Neuron $108,17-32$. doi: 10.1016/j.neuron.2020.09.036

Saleeba, C., Dempsey, B., Le, S., Goodchild, A., and McMullan, S. (2019). A student's guide to neural circuit tracing. Front. Neurosci. 13:897. doi: 10.3389/ fnins.2019.00897

Sauer, B., and Henderson, N. (1988). Site-specific DNA recombination in mammalian cells by the Cre recombinase of bacteriophage P1. Proc. Natl. Acad. Sci. U.S.A 85, 5166-5170. doi: 10.1073/pnas.85.14.5166

Scheffer, L. K., Xu, C. S., Januszewski, M., Lu, Z., Takemura, S. Y., Hayworth, K. J., et al. (2020). A connectome and analysis of the adult drosophila central brain. eLife 9:e57443. doi: 10.7554/ELIFE.57443

Schmidt, H., Gour, A., Straehle, J., Boergens, K. M., Brecht, M., and Helmstaedter, M. (2017). Axonal synapse sorting in medial entorhinal cortex. Nature 549, 469-475. doi: 10.1038/nature24005

Schnell, M. J., McGettigan, J. P., Wirblich, C., and Papaneri, A. (2010). The cell biology of rabies virus: using stealth to reach the brain. Nat. Rev. Microbiol. 8, 51-61. doi: 10.1038/nrmicro2260

Schwarz, M. K., and Remy, S. (2019). Rabies virus-mediated connectivity tracing from single neurons. J. Neurosci. Methods 325:108365. doi: 10.1016/j.jneumeth. 2019.108365

Shang, C., Liu, A., Li, D., Xie, Z., Chen, Z., Huang, M., et al. (2019). A subcortical excitatory circuit for sensory-triggered predatory hunting in mice. Nat. Neurosci. 22, 909-920. doi: 10.1038/s41593-019-0405-4

Shearin, H. K., Quinn, C. D., Mackin, R. D., Macdonald, I. S., and Stowers, R. S. (2018). t-GRASP, a targeted GRASP for assessing neuronal connectivity. J. Neurosci. Methods 306, 94-102. doi: 10.1016/j.jneumeth.2018.05.014

Skocek, O., Nöbauer, T., Weilguny, L., Traub, F. M., Xia, C. N., Molodtsov, M. I., et al. (2018). Author Correction: High-speed volumetric imaging of neuronal activity in freely moving rodents. Nat. Methods 15, 469-469. doi: 10.1038/ s41592-018-0034-y

Smith, K. S., Bucci, D. J., Luikart, B. W., and Mahler, S. V. (2016). DREADDs: use and application in behavioral neuroscience. Behav. Neurosci. 130, 137-155. doi: $10.1037 /$ bne 0000135

Soden, M. E., Chung, A. S., Cuevas, B., Resnick, J. M., Awatramani, R., and Zweifel, L. S. (2020). Anatomic resolution of neurotransmitter-specific projections to the VTA reveals diversity of GABAergic inputs. Nat. Neurosci. 23, 968-980. doi: 10.1038/s41593-020-0657-z

Sofroniew, N. J., Flickinger, D., King, J., and Svoboda, K. (2016). A large field of view two-photon mesoscope with subcellular resolution for in vivo imaging. eLife 5:e14472. doi: 10.7554/eLife.14472

Song, J. H., Lucaci, D., Calangiu, I., Brown, M. T. C., Park, J. S., Kim, J., et al. (2018). Combining mGRASP and optogenetics enables high-resolution functional mapping of descending cortical projections. Cell Rep. 24, 1071-1080. doi: 10.1016/j.celrep.2018.06.076

Soudais, C., Skander, N., and Kremer, E. J. (2003). Long-term in vivo transduction of neurons throughout the rat central nervous system using novel helperdependent CAV-2 vectors. FASEB J. 18, 1-20. doi: 10.1096/fj.03-0438fje

Sporns, O., Tononi, G., and Kötter, R. (2005). The human connectome: a structural description of the human brain. PLoS Comput. Biol. 1:e42. doi: 10.1371/journal. pcbi.0010042

Stephan, K. E., Kamper, L., Bozkurt, A., Burns, G. A., Young, M. P., and Kötter, R. (2001). Advanced database methodology for the collation of connectivity data on the macaque brain (CoCoMac). Philos. Trans. R. Soc. Lond. B. Bio.l Sci. 356, 1159-1186. doi: 10.1098/rstb.2001.0908

Sternson, S. M., and Roth, B. L. (2014). Chemogenetic tools to interrogate brain functions. Annu. Rev. Neurosci. 37, 387-407. doi: 10.1146/annurev-neuro071013-014048

Sun, Q., Li, X., Ren, M., Zhao, M., Zhong, Q., Ren, Y., et al. (2019). A whole-brain map of long-range inputs to GABAergic interneurons in the mouse medial prefrontal cortex. Nat. Neurosci. 22, 1357-1370. doi: 10.1038/s41593-0190429-9 
Sun, X. R., Badura, A., Pacheco, D. A., Lynch, L. A., Schneider, E. R., Taylor, M. P., et al. (2013). Fast GCaMPs for improved tracking of neuronal activity. Nat. Commun. 4:2170. doi: 10.1038/ncomms 3170

Sun, Y., Nguyen, A. Q., Nguyen, J. P., Le, L., Saur, D., Choi, J., et al. (2014). Cell-type-specific circuit connectivity of hippocampal CA1 revealed through Cre-dependent rabies tracing. Cell Rep. 7, 269-280. doi: 10.1016/j.celrep.2014. 02.030

Sych, Y., Chernysheva, M., Sumanovski, L. T., and Helmchen, F. (2019). Highdensity multi-fiber photometry for studying large-scale brain circuit dynamics. Nat. Methods 16, 553-560. doi: 10.1038/s41592-019-0400-4

Tallini, Y. N., Ohkura, M., Choi, B.-R., Ji, G., Imoto, K., Doran, R., et al. (2006). Imaging cellular signals in the heart in vivo: cardiac expression of the highsignal Ca2+ indicator GCaMP2. Proc Natl. Acad. Sci. U.S.A. 103, 4753-4758. doi: 10.1073/pnas.0509378103

Tasaka, G.-I., Feigin, L., Maor, I., Groysman, M., DeNardo, L. A., Schiavo, J. K., et al. (2020). The temporal association cortex plays a key role in auditory-driven maternal plasticity. Neuron 107, 566-579.e7. doi: 10.1016/j.neuron.2020.05.004

Tervo, D. G. R., Hwang, B.-Y., Viswanathan, S., Gaj, T., Lavzin, M., Ritola, K. D., et al. (2016). A designer AAV variant permits efficient retrograde access to projection neurons. Neuron 92, 372-382. doi: 10.1016/j.neuron.2016.09.021

Tian, J., Huang, R., Cohen, J. Y., Osakada, F., Kobak, D., Machens, C. K., et al. (2016). Distributed and mixed information in monosynaptic inputs to dopamine neurons. Neuron 91, 1374-1389. doi: 10.1016/j.neuron.2016.08.018

Tian, L., Hires, S. A., Mao, T., Huber, D., Chiappe, M. E., Chalasani, S. H., et al. (2009). Imaging neural activity in worms, flies and mice with improved GCaMP calcium indicators. Nat. Methods 6, 875-881. doi: 10.1038/nmeth.1398

Ugolini, G. (1995). Specificity of rabies virus as a transneuronal tracer of motor networks: transfer from hypoglossal motoneurons to connected second-order and higher order central nervous system cell groups. J. Comp. Neurol. 356, 457-480. doi: 10.1002/cne. 903560312

Ugolini, G., Kuypers, H. G. J. M., and Simmons, A. (1987). Retrograde transneuronal transfer of Herpes simplex virus type 1 (HSV 1) from motoneurones. Brain Res. 422, 242-256. doi: 10.1016/0006-8993(87)90931-0

Unger, E. K., Keller, J. P., Altermatt, M., Liang, R., Matsui, A., Dong, C., et al. (2020). Directed evolution of a selective and sensitive serotonin sensor via machine learning. Cell 183, 1986-2002.e26. doi: 10.1016/j.cell.2020.11.040

Van Essen, D. C., Smith, S. M., Barch, D. M., Behrens, T. E. J., Yacoub, E., and Ugurbil, K. (2013). The WU-minn human connectome project: an overview. Neuroimage 80, 62-79. doi: 10.1016/j.neuroimage.2013.05.041

Vardy, E., Robinson, J. E., Li, C., Olsen, R. H. J., DiBerto, J. F., Giguere, P. M., et al. (2015). A new DREADD facilitates the multiplexed chemogenetic interrogation of behavior. Neuron 86, 936-946. doi: 10.1016/j.neuron.2015.03.065

Wall, N. R., Wickersham, I. R., Cetin, A., De La Parra, M., Callaway, E. M., and Anderson, D. J. (2010). Monosynaptic circuit tracing in vivo through Cre-dependent targeting and complementation of modified rabies virus. Proc. Natl. Acad. Sci. U.S.A. 107, 21848-21853. doi: 10.1073/pnas.10117 56107

Wang, L., Gillis-Smith, S., Peng, Y., Zhang, J., Chen, X., Salzman, C. D., et al. (2018). The coding of valence and identity in the mammalian taste system. Nature 558, 127-131. doi: 10.1038/s41586-018-0165-4

Wang, Q., Ding, S.-L., Li, Y., Royall, J., Feng, D., Lesnar, P., et al. (2020). The allen mouse brain common coordinate framework: a 3D reference atlas. Cell 181, 936-953.e20. doi: 10.1016/j.cell.2020.04.007

Wang, Q., Henry, A. M., Harris, J. A., Oh, S. W., Joines, K. M., Nyhus, J., et al. (2014). Systematic comparison of adeno-associated virus and biotinylated dextran amine reveals equivalent sensitivity between tracers and novel projection targets in the mouse brain. J. Comp. Neurol. 522, 1989-2012. doi: $10.1002 / \mathrm{cne} .23567$

White, J. G., Southgate, E., Thomson, J. N., and Brenner, S. (1986). The structure of the nervous system of the nematode caenorhabditis elegans. Philos. Trans. $R$. Soc. Lond. B Biol. Sci. Ser. B 314, 1-340. doi: 10.1098/rstb.1986.0056

Wickersham, I. R., Finke, S., Conzelmann, K.-K., and Callaway, E. M. (2007a). Retrograde neuronal tracing with a deletion-mutant rabies virus. Nat. Methods 4, 47-49. doi: 10.1038/nmeth999
Wickersham, I. R., Lyon, D. C., Barnard, R. J. O., Mori, T., Finke, S., Conzelmann, K.-K., et al. (2007b). Monosynaptic restriction of transsynaptic tracing from single, genetically targeted neurons. Neuron 53, 639-647. doi: 10.1016/j.neuron. 2007.01.033

Wilson, D. E., Whitney, D. E., Scholl, B., and Fitzpatrick, D. (2016). Orientation selectivity and the functional clustering of synaptic inputs in primary visual cortex. Nat. Neurosci. 19, 1003-1009. doi: 10.1038/nn.4323

Winnubst, J., Bas, E., Ferreira, T. A., Wu, Z., Economo, M. N., Edson, P., et al. (2019). Reconstruction of 1,000 projection neurons reveals new cell types and organization of long-range connectivity in the mouse brain. Cell 179, 268-281.e13. doi: 10.1016/j.cell.2019.07.042

Wu, J., Abdelfattah, A. S., Zhou, H., Ruangkittisakul, A., Qian, Y., Ballanyi, K., et al. (2018). Genetically encoded glutamate indicators with altered color and topology. ACS Chem. Biol. 13, 1832-1837. doi: 10.1021/acschembio.7b01085

Xu, X., Holmes, T. C., Luo, M.-H., Beier, K. T., Horwitz, G. D., Zhao, F., et al. (2020). Viral vectors for neural circuit mapping and recent advances in transsynaptic anterograde tracers. Neuron 107, 1029-1047. doi: 10.1016/j.neuron. 2020.07.010

Yamawaki, N., Li, X., Lambot, L., Ren, L. Y., Radulovic, J., and Shepherd, G. M. G. (2020). Long-range inhibitory intersection of a retrosplenial thalamocortical circuit by apical tuft-targeting CA1 neurons. Nat. Neurosci. 22, 1-15. doi: 10. 1038/s41593-019-0355-x

Yizhar, O., Fenno, L. E., Davidson, T. J., Mogri, M., and Deisseroth, K. (2011). Optogenetics in neural systems. Neuron 71, 9-34. doi: 10.1016/j.neuron.2011. 06.004

Zeng, H., and Sanes, J. R. (2017). Neuronal cell-type classification: challenges, opportunities and the path forward. Nature 18, 530-546. doi: 10.1038/nrn. 2017.85

Zhang, F., Prigge, M., Beyrière, F., Tsunoda, S. P., Mattis, J., Yizhar, O., et al. (2008). Red-shifted optogenetic excitation: a tool for fast neural control derived from volvox carteri. Nat. Neurosci. 11, 631-633. doi: 10.1038/nn.2120

Zhang, F., Wang, L.-P., Brauner, M., Liewald, J. F., Kay, K., Watzke, N., et al. (2007). Multimodal fast optical interrogation of neural circuitry. Nature 446, 633-639. doi: 10.1038/nature05744

Zhao, Y., Araki, S., Jiahui, W., Teramoto, T., Chang, Y.-F., Nakano, M., et al. (2011). An expanded palette of genetically encoded Ca2+ indicators. Science 333, 1888-1891. doi: 10.1126/science. 1208592

Zingg, B., Chou, X.-L., Zhang, Z.-G., Mesik, L., Liang, F., Tao, H. W., et al. (2017). AAV-mediated anterograde transsynaptic tagging: mapping corticocollicular input-defined neural pathways for defense behaviors. Neuron 93, 33-47. doi: 10.1016/j.neuron.2016.11.045

Zingg, B., Hintiryan, H., Gou, L., Song, M. Y., Bay, M., Bienkowski, M. S., et al. (2014). Neural networks of the mouse neocortex. Cell 156, 1096-1111. doi: 10.1016/j.cell.2014.02.023

Zingg, B., Peng, B., Huang, J., Tao, H. W., and Zhang, L. I. (2020). Synaptic specificity and application of anterograde transsynaptic AAV for probing neural circuitry. J. Neurosci. 40, 3250-3267. doi: 10.1523/JNEUROSCI.2158- 19.2020

Zolnik, T. A., Ledderose, J., Toumazou, M., Trimbuch, T., Oram, T., Rosenmund, C., et al. (2020). Layer $6 \mathrm{~b}$ is driven by intracortical long-range projection neurons. Cell Rep 30, 3492-3505.e5. doi: 10.1016/j.celrep.2020.02.044

Zong, W., Wu, R., Li, M., Hu, Y., Li, Y., Li, J., et al. (2017). Fast high-resolution miniature two-photon microscopy for brain imaging in freely behaving mice. Nat. Methods 14, 713-719. doi: 10.1038/nmeth.4305

Conflict of Interest: The authors declare that the research was conducted in the absence of any commercial or financial relationships that could be construed as a potential conflict of interest.

Copyright (c) 2021 Yook, Kim and Kim. This is an open-access article distributed under the terms of the Creative Commons Attribution License (CC BY). The use, distribution or reproduction in other forums is permitted, provided the original author(s) and the copyright owner(s) are credited and that the original publication in this journal is cited, in accordance with accepted academic practice. No use, distribution or reproduction is permitted which does not comply with these terms. 